\title{
The possible role of corticosterone in regulating sodium and potassium concentrations in human milk
}

\author{
Maciej Zietek ${ }^{1} \oplus$, Diana Sochaczewska², Malgorzata Swiatkowska-Freund ${ }^{3} \oplus$, \\ Zbigniew Celewicz ${ }^{1}{ }^{(1)}$, Malgorzata Szczuko ${ }^{4}$ (D) \\ ${ }^{1}$ Department of Perinatology, Obstetrics and Gynecology, Pomeranian Medical University, Szczecin, Poland \\ ${ }^{2}$ Department of Neonatology, Pomeranian Medical University in Szczecin, Police, Poland \\ ${ }^{3}$ Department of Obstetrics, Medical University in Gdansk, Poland \\ ${ }^{4}$ Department of Human Nutrition and Metabolomics, Pomeranian Medical University in Szczecin, Poland
}

\begin{abstract}
Objectives: The aim of the study was to find the presence of corticosterone as a regular human milk constituent. We have evaluated the correlation of concentrations between the analyzed hormone and sodium and potassium in breast milk and serum.

Material and methods: Hand expressing breast milk samples and median cubital vein blood samples had been taken from 69 healthy, lactating women in early puerperium period (between the $3^{\text {rd }}$ and $10^{\text {th }}$ day) twice, before and after breastfeeding. Corticosterone concentrations in human plasma and breast milk were determined by radioimmunoassayed method. Direct assays were performed before and after breastfeeding, twice. The serum and milk sodium and potassium concentrations were estimated by Flame Emission analyzer CIBA-Corning 480, equipped with an automatic diluter.

Results: Corticosterone was found in all milk samples, which is an original observation, and its concentration in milk was a few times lower than in serum. Its concentration values in human serum when were not higher than $3 \mathrm{nmol} / \mathrm{L}(\mathrm{n}=108)$ positively correlated with its concentrations in milk, and those exceeding $3 \mathrm{nmol} / \mathrm{L}(\mathrm{n}=30)$ have demonstrated a negative correlation. An original finding has shown a positive correlation between concentrations of corticosterone in human serum and of potassium in human milk $(r=0.018, p<0.03)$. An attempt was also made to determine the presence of aldosterone in breast milk, but the radioimmunoassay did not reveal its presence.

Conclusions: The results confirm a relation between potassium concentration in milk and serum corticosterone concentration delivered to mammal gland with blood.
\end{abstract}

Key words: corticosterone; sodium; potassium; human breast milk

Ginekologia Polska

\section{INTRODUCTION}

Decreased proportion of sodium $(\mathrm{Na})$ and potassium $(\mathrm{K})$ ions in breast milk is an objective biomarker of mammary gland progress toward copious mature milk production over the first week postpartum [1]. Low milk supply is one of the most frequently cited reasons for early breastfeeding cessation, moreover, elevated proportion Na:K in milk was predictive of early weaning [2,3]. The reasons why in human milk potassium concentration is a few times higher and sodium concentration a few times lower than in human serum so far have not been satisfactorily explained.
It is well known that steroid hormones are mostly responsible for potassium and sodium excretion in the kidney and aldosterone has the major mineralocorticoid activity in the regulation of these electrolytes' concentrations. Its secretion is regulated, apart from ACTH, by an increase in blood content of angiotensin II and $\mathrm{K}+$ level where the response is mediated by mineralocorticoid receptor [4]. Mineralocorticoids, including aldosterone increase the distal renal tubular sodium ions reabsorption from the glomerular filtrate, while increasing the secretion of potassium 
ions. The sodium absorption in renal tubules is regulated via mineralocorticoid receptor (MR) by corticosteroids (including aldosterone and cortisol) in humans and corticosterone mostly acts in rodents. Similarly, they act on the gastrointestinal gland receptors, retaining sodium ions in the body and increase the volume of extracellular fluid [5]. In muscle and nerve cells, they increase the potassium content and at the same time reduce the sodium content [6].

The role of aldosterone and corticosterone in breast milk has not been yet described, especially their effect on sodium and potassium content. The content of free (physiologically active) glucocorticoids is regulated by two mechanisms. One is associated with pituitary gland ACTH secretion and the second consists in the production of human corticosteroid binding globulin (CBG, transcortin) by the liver and reduction of blood content of free hormones, not related to plasma hormone binding globulins [7].

It is considered that the exchange of electrolytes in secretory epithelium of mammary gland (MEC, mammary epithelial cells) is intensified by prolactin (PRL). This opinion is supported by experiments conducted on lactating rabbits. PRL administered for these animals causes an increase of potassium and lactose concentrations and decrease of sodium concentration in their milk [1]. However, in the literature of subject there are no convincing proofs for PRL effects on sodium and potassium concentrations in human milk. This missing information justifies posing a question on the role of other hormones in regulating sodium and potassium concentrations in milk. Deoxycorticosterone (DOC) is an adrenal gland steroid hormone possessing mineralocorticoid activity weaker than aldosterone, but stronger than corticosterone and cortisol, furthermore, the activity of the latter one is the weakest [2]. It acts as a precursor to aldosterone. Besides, the main activity of corticosterone and cortisol is of glucocorticoid character [3]. Different degree of mineralocorticoid activity of these steroids depends on the ability of each of them to bind to specific receptors $[4,5]$. In the available literature, we have not found any information on the occurrence of corticosterone in human milk. Cortisol $(F)$ is a regular constituent of human milk. Its concentration in milk shows diurnal circadian variation, which is in accordance with circadian variation of cortisol concentration in serum, and of potassium concentration in milk, and is opposite to circadian variation of sodium concentration in milk [7]. When in milk cortisol concentration increases, sodium concentration decreases, whereas in the same time potassium increases. Thus, higher cortisol concentration exerts analogue influence on the exchange of sodium and potassium in mammary glands, as aldosterone in kidneys. However, kaliuretic effect of aldosterone occurs only if there is an excess of potassium in serum [8]. The diurnal circadian variation of $\mathrm{F}$ concentration in milk measured by radioimmunoassay of unchromatographed extracts has been proved by Kennan et al. [9]. The authors, in order to confirm that $\mathrm{F}$ affects milk electrolyte concentrations, applied dexamethasone suppression in five lactating women. In four of them, a significant decrease of sodium and increase of potassium concentration in milk have been observed. These results are opposite to expected, as dexamethasone decreases $F$ secretion. The authors have not found a convincing explanation of these contradictions. Further research is required in order to explain a mechanism regulating sodium and potassium concentrations in human milk, especially research on corticosterone and aldosterone.

Katoh et al. [6], study has demonstrated a significant positive correlation between both the glucocorticoids induced cardiac hypertrophy and hypertrophic gene expression and the level of sodium.

\section{Objectives}

The aim of this work is to find out if corticosterone is a regular constituent of human milk. Also, it is important to answer the question if there is a correlation between concentrations of corticosterone in serum, and sodium and potassium in milk, and corticosterone in milk (if it occurs), and sodium and potassium in milk.

\section{MATERIAL AND METHODS}

This study was approved by the ethics committee of the Pomeranian Medical University in Szczecin. All patients provided written consent before the inclusion in the study. Sixty-nine healthy, lactating women in early puerperium period (between the 3rd and 10th day) were included in the study. The studied women were between 20 and 38 years of age (mean $29.4 \pm 4.6$ years), currently breastfeeding only. The courses of pregnancies were uncomplicated, and all the analyzed women delivered by vaginal route term gestation (39 0/7 to $406 / 7$ weeks). Hand expressing breast milk samples and median cubital vein blood samples had been taken in days 3 to 10 of puerperium, in the morning, before and immediately after breastfeeding, twice. Samples were collected after overnight fasting and none of analyzed women was treated with medicaments.

Corticosterone concentrations in human serum and breast milk were radioimmunoassayed (RIA), using a commercial Radioimmunoassay kit (Immunotech SA, Marseille Cedex, France). Direct assays were performed before and after breastfeeding.

Corticosterone concentration was assayed with the previous samples' extraction and was repurified by Celite column chromatography prior to analyses. The labelled $\left[{ }^{3} \mathrm{H}\right]$ corticosterone and dextrane-coated charcoal was used to separate free hormone from hormone bound with antibody (ICN Biomedicals, CA, USA). Impulses were counted 
with a scintillation beta radiation counter Pharmacia Wallac 1409/1411 (LKB Co., Victoria, Australia).

The breast milk sodium and potassium concentrations were estimated by Flame Emission analyzer CIBA-Corning 480 , equipped with an automatic diluter.

\section{Statistical analysis}

The statistical significance of differences of mean concentrations was calculated by means of non-parametric Wilcoxon's rank sum test, on the assumption that significance coefficient $p<0.05$, and correlations between concentrations of analyzed substances were established by means of non-parametric method, using Spearman's rank correlation coefficient. A Cumulative Distribution Function (CDF) was calculated to check the probability and correlations presence between the variables in specified five ranges of values.

\section{RESULTS}

We proved that corticosterone is a regular constituent of human milk. The presence of corticosterone was revealed in all milk samples in few times lower concentration than in serum ( $p<0.000001$ ) (Fig 1.). The comparison of concen- trations of corticosterone in serum and milk samples and ions $\mathrm{Na}, \mathrm{K}$ in milk samples taken before and after breastfeeding has not shown statistically significant differences (Fig 2.), therefore their values were analyzed together, and for these two groups of results common averages were calculated (Tab. 1). The correlation between corticosterone concentrations in consecutive concentration ranges in serum and its concentrations in milk has been presented in Table 2. If corticosterone concentration in human serum was smaller than $3 \mathrm{nmol} / \mathrm{L}(\mathrm{n}=108)$, then it would demonstrate a positive correlation with its concentration in milk $(r=0.29$; $\mathrm{p}<0.002)$, and if it was higher $(\mathrm{n}=30)$, a negative correlation with its concentration in milk would be demonstrated $(r=-0.37 ; p<0.04)$ (Tab. 2).

Potassium concentration in milk showed a positive correlation with corticosterone concentration in human serum $(r=0.18 ; p<0.03)$, whereas sodium concentration in milk did not reveal such a correlation, but an opposite tendency has been noticed ( $r=-0.10 ; p<0.23$ ). No significant correlation between the concentrations of corticosterone and sodium $(r=-0.15 ; p<0.08)$ or corticosterone and potassium $(r=0.14$; $p<0.09$ ) in milk was observed (Tab. 3).

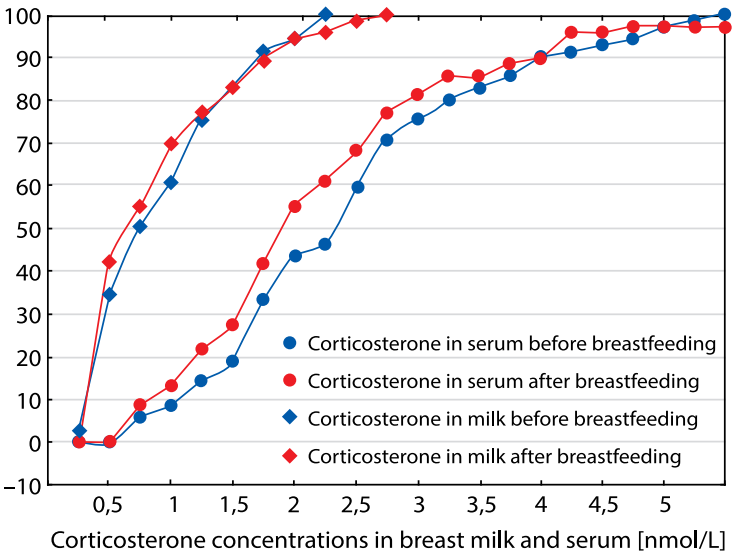

Figure 1. A cumulative distribution of corticosterone concentrations in serum and breast milk before and after feeding in the analysed women

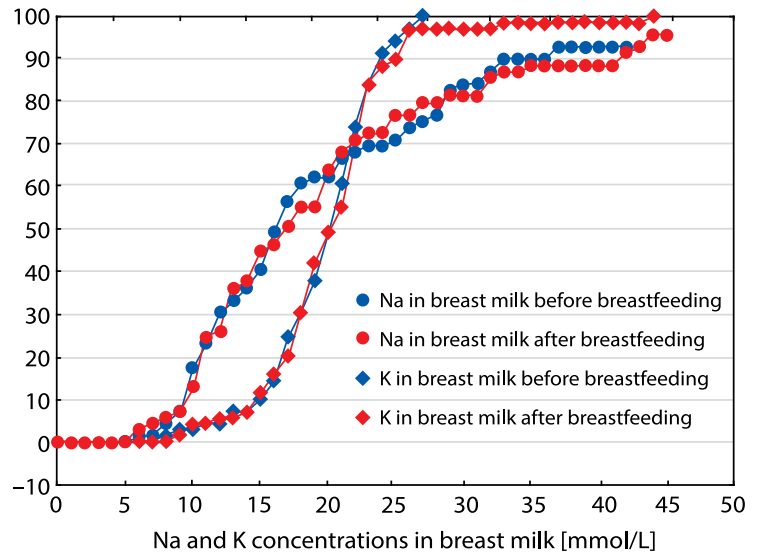

Figure 2. A cumulative distribution of sodium and potassium concentrations in breast milk before and after feeding in the analysed women; $\mathrm{Na}$ - sodium; $\mathrm{K}$ - potassium

Table 1. Mean serum $\left(\mathrm{B}_{\mathrm{s}}\right)$ and breast milk $\left(\mathrm{B}_{\mathrm{m}}\right)$ corticosterone concentrations and $\mathrm{Na}$ and $\mathrm{K}$ breast milk concentrations in the analysed women $(n=138)$

\begin{tabular}{|l|l|l|l|}
\hline & $\mathbf{X} \pm$ SD & Median & Range \\
\hline$B_{\mathrm{s}}(\mathrm{nmol} / \mathrm{L})$ & $2.36 \pm 1.60$ & 2.05 & $0.52-15.32$ \\
\hline $\mathrm{B}_{\mathrm{m}}(\mathrm{nmol} / \mathrm{L})$ & $0.86 \pm 0.58$ & 0.69 & $0.03-2.60$ \\
\hline $\mathrm{Na}(\mathrm{mmol} / \mathrm{L})$ & $20.09 \pm 13.78$ & 16.00 & $5.00-85.00$ \\
\hline $\mathrm{K}(\mathrm{mmol} / \mathrm{L})$ & $19.25 \pm 4.49$ & 20.00 & $7.00-43.00$ \\
\hline
\end{tabular}

SD - standard deviation 
Table 2. Correlations between serum corticosterone concentrations $\left(B_{s}\right)$ and breast milk corticosterone concentrations $\left(B_{m}\right)$ in several ranges of values (Spearman's rank correlation coefficient)

\begin{tabular}{|c|c|c|c|c|c|}
\hline \multirow{2}{*}{ n } & \multirow{2}{*}{$B_{s}(\mathrm{nmol} / \mathrm{L})$} & \multicolumn{2}{|c|}{$B_{m}(\mathrm{nmol} / \mathrm{L})$} & \multirow{2}{*}{$r$} & \multirow{2}{*}{ p value } \\
\hline & & Median & Range & & \\
\hline 15 & $\mathrm{n}<1$ & 0.43 & $0.087-1.705$ & \multirow{3}{*}{0.29} & \multirow{3}{*}{0.002} \\
\hline 53 & $1 \leq n<2$ & 0.66 & $0.289-2.601$ & & \\
\hline 40 & $2 \leq n<3$ & 1.03 & $0.029-2.427$ & & \\
\hline 16 & $3 \leq n<4$ & 0.64 & $0.289-2.427$ & \multirow{2}{*}{-0.37} & \multirow{2}{*}{0.04} \\
\hline 14 & $4 \leq n<5$ & 0.46 & $0.289-1.965$ & & \\
\hline
\end{tabular}

\begin{tabular}{|c|c|c|c|c|c|c|c|c|c|}
\hline \multirow{2}{*}{$\mathbf{n}$} & \multirow{2}{*}{$\mathrm{B}_{\mathrm{s}}(\mathrm{nmol} / \mathrm{L})$} & \multicolumn{4}{|c|}{$\mathrm{K}(\mathrm{mmol} / \mathrm{l})$} & \multicolumn{4}{|c|}{$\mathrm{Na}(\mathrm{mmol} / \mathrm{l})$} \\
\hline & & Median & Range & $r$ & $p<$ & Median & Range & $r$ & $p$-value \\
\hline 15 & $\mathrm{n}<1$ & 19 & $9-25$ & \multirow{5}{*}{0.18} & \multirow{5}{*}{0.03} & 19 & $7-85$ & \multirow{5}{*}{-0.10} & \multirow{5}{*}{ N.S. } \\
\hline 53 & $1 \leq n<2$ & 19 & $7-43$ & & & 19 & $6-85$ & & \\
\hline 40 & $2 \leq n<3$ & 20 & $8-26$ & & & 14.5 & $5-36$ & & \\
\hline 16 & $3 \leq n<4$ & 21 & $11-26$ & & & 15 & $9-51$ & & \\
\hline 14 & $4 \leq n<5$ & 21 & $15-25$ & & & 13 & $9-41$ & & \\
\hline
\end{tabular}

N.S. $-? ? ?$

\section{DISCUSSION}

The principal endogenous glucocorticoids such as cortisol and corticosterone play an important role in metabolism, stress and adaptation. Although corticosterone concentration is 10-20-fold lower in human blood when compared to cortisol level, it has a significant glucocorticoid and mineralocorticoid activity. Corticosterone is synthesized in the zona fasciculata of the adrenal cortex where converted to aldosterone in the route to mineralocorticoid biosynthesis. Mineralocorticoids, especially aldosterone are responsible for increase the reabsorption of $\mathrm{Na}$ and the excretion of $\mathrm{K}$ in the kidney, leading to an increase in blood volume and blood pressure. The role and activity of corticosterone has been vastly investigated in animal models, but there is a little known about its presence and role in human milk. No data has been found about potential role of endogenous corticosterone in ions secretion control in mammary gland. In turn there are studies showing that exposure of neonates to maternally derived milk corticosterone can alter the cell-mediated immune response and impair the neonatal resistance to infection [10].

To the best of our knowledge, this study is the first to demonstrate that corticosterone is a regular human milk constituent - present in each its sample and our results differ from those received by Alexandrová and Machno [11]. Using the thin layer chromatography and measured the concentration of cortisol by CBG assay, they found cortisol in human milk but did not identify corticosterone. Although the presence of milk corticosteroid binding globulin (CBG) identical to $C B G$ in blood serum has been demonstrated in the late seventies [12], the corticosterone presence in milk became possible only thanks to development of radioimmunoassay methods of hormones identification. As Misao et al. [13], demonstrated, CBG is not only binding of cortisol but also corticosterone and progesterone.

Our study presents a correlation between corticosterone concentrations in serum and milk. Its concentration in milk is 2-3 times lower than in serum. This proportion in humans is similar to that observed in rats [14]. In our study corticosterone breast milk concentration fluctuations depend on and correlate with hormone level changes in serum. The correlation is observed to be positive when serum corticosterone concentrations do not exceed $3 \mathrm{nmol} / \mathrm{L}$, but in case of exceeding above this value the correlation shows a negative tendency. It is possible that lower than in serum corticosterone concentration in milk, protects the offspring against excessive supply of corticosterone. Also, in cases where corticosterone concentration in serum increases over $3 \mathrm{nmol} / \mathrm{L}$, which leads to decreasing corticosterone concentration in milk, the newborns' protecting mechanism against surplus supply of this hormone shall be considered.

The mechanism that leads to lower corticosterone concentration in milk may consist in its conversion into less active 11- $\beta$-dehydrocorticosterone, which catalysed by hydroxysteroid 11- $\beta$-dehydrogenase (11 $\beta$-HSD1). This enzyme occurs in rat's mammary glands, but in available literature 
there is no information on its occurrence in women's mammary glands. An occurrence of this enzyme in human placenta is regarded as a circumstance, which protects fetus against excess of corticosterone and cortisol $[15,16]$.

High corticosterone serum concentrations studied on animal models are observed to decrease maternal care, plasma oxytocin levels, milk consumption by the pups and the activation of oxytocinergic neurons in hypothalamic nuclei [17]. An increase of $11 \beta$-hydroxysteroid dehydrogenase I activity may result in hyperadrenalism [18]. A selective inhibitor for 11ß-HSD1 PF915275 (PF; 4'-cyano-biphenyl-4-sulfonic acid (6-amino-pyridin-2-yl)-amide) may be useful as agent alleviating $11 \beta-H S D 1$ activity in way to treat hyperadrenalism [18].

There is a little known about ions extraction in breast milk. It has been demonstrated that an elevated ratio of breast milk sodium to potassium concentration was predictive of early weaning in breastfeeding women and may be considered as a biomarker of lack of progress toward mature milk production [3]. Sodium ( $\mathrm{Na})$, potassium $(\mathrm{K})$, and the ratio Na:K in human milk may also indicate the secretory activation or inflammation in the breast [19]. Circadian variation of sodium concentration in milk positively correlates with circadian variation of cortisol concentrations both in serum and milk, but negatively correlates to circadian variation of potassium concentration in milk [8]. Our research has shown a presence of correlation between serum corticosterone and breast milk potassium concentrations, regardless of corticosterone concentration value in milk. We presume that serum corticosterone delivered by adrenal cortex may cause an increase of potassium concentration in milk. In the available literature, also no information is found on corticosterone influence on sodium and potassium concentrations in human milk.

Research conducted by other authors may be regarded to support these results, as no correlation has been found between sodium and potassium concentrations in urine and in colostrum [20,21], and between their diurnal excretion in urine and milk [22]. There are studies conducted on animal models, showing a correlation of the composition and the basic content of some minerals including sodium and potassium of colostrum depending on the season of calving and lactation [23]. The concentrations of some micronutrients in human colostrum and mature milk may also vary during lactation, including a reduction in $\mathrm{Fe}, \mathrm{Zn}, \mathrm{K}$ and $\mathrm{Na}$ and an increase in Ca and P [24].

\section{CONCLUSIONS}

We conclude that endogenous serum corticosterone is a stable human milk content. Serum corticosterone may influence ions extraction by increasing potassium concen- tration in milk, but not sodium. This thesis requires further research, especially on interrelationships of different factors regulating concentrations of these electrolytes in milk.

\section{Acknowledgements}

The authors would like to express their gratitude for a research grant number 4PO5E 14614 obtained from the Scientific Research Committee, which has allowed to carry out this work.

\section{Conflict of interest}

The authors report no conflict of interest.

\section{REFERENCES}

1. Neville MC, Allen JC, Archer PC, et al. Studies in human lactation: milk volume and nutrient composition during weaning and lactogenesis. Am J Clin Nutr. 1991; 54(1): 81-92, doi: 10.1093/ajcn/54.1.81, indexed in Pubmed: 2058592.

2. Li R, Fein SB, Chen J, et al. Why mothers stop breastfeeding: mothers self-reported reasons for stopping during the first year. Pediatrics. 2008; 122 Suppl 2: S69-S76, doi: 10.1542/peds.2008-1315i, indexed in Pubmed: 18829834.

3. Murase M, Wagner EA, J Chantry C, et al. The Relation between Breast Milk Sodium to Potassium Ratio and Maternal Report of a Milk Supply Concern. J Pediatr. 2017; 181: 294-297.e3, doi: 10.1016/j.jpeds.2016.10.044, indexed in Pubmed: 27871690.

4. Emmett M, Mehta A. Gastrointestinal potassium binding-more than just lowering serum $[\mathrm{K}(+)]$ : patiromer, potassium balance, and the renin angiotensin aldosterone axis. Kidney Int. 2016; 90(3): 484-486, doi: 10.1016/j.kint.2016.06.031, indexed in Pubmed: 27521112.

5. Armanini D, Bordin L, Donà G, et al. Relationship between sodium, pentraxin-3 and aldosterone in inflammation and cardiovascular risk. J Clin Hypertens (Greenwich). 2018; 20(5): 932-934, doi: 10.1111/jch.13298, indexed in Pubmed: 29700955.

6. Katoh D, Hongo K, Ito K, et al. Corticosteroids increase intracellular free sodium ion concentration via glucocorticoid receptor pathway in cultured neonatal rat cardiomyocytes. Int J Cardiol Heart Vessel. 2014; 3: 49-56, doi: 10.1016/j.ijchv.2014.03.001, indexed in Pubmed: 29450170.

7. Eyal O, Limor R, Oren A, et al. Establishing Normal Ranges of Basal and ACTH-Stimulated Serum Free Cortisol in Children. Horm Res Paediatr. 2016; 86(2): 94-99, doi: 10.1159/000447946, indexed in Pubmed: 27437687.

8. Rabinowitz L. Aldosterone and potassium homeostasis. Kidney Int. 1996; 49(6): 1738-1742, doi: 10.1038/ki.1996.258, indexed in Pubmed: 8743488 .

9. Keenan BS, Buzek SW, Garza C. Cortisol and its possible role in regulation of sodium and potassium in human milk. Am J Physiol. 1983; 244(3): E253-E261, doi: 10.1152/ajpendo.1983.244.3.E253, indexed in Pubmed: 6829754.

10. Zahwa H, Yorty JL, Bonneau RH. Elevated maternal corticosterone during lactation hinders the neonatal adaptive immune response to herpes simplex virus (HSV) infection. Brain Behav Immun. 2008; 22(3): 339-353, doi: 10.1016/j.bbi.2007.08.012, indexed in Pubmed: 17950573.

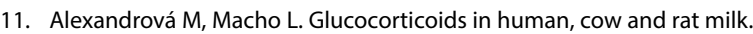
Endocrinol Exp. 1983; 17(3-4): 183-189, indexed in Pubmed: 6606561.

12. Rosner W, Beers PC, Awan T, et al. Identification of corticosteroid-binding globulin in human milk: measurement with a filter disk assay. J Clin Endocrinol Metab. 1976; 42(6): 1064-1073, doi: 10.1210/jcem-42-6-1064, indexed in Pubmed: 932172.

13. Misao R, Hori M, Ichigo $\mathrm{S}$, et al. Corticosteroid-binding globulin mRNA levels in human uterine endometrium. Steroids. 1994; 59(10): 603-607, doi: 10.1016/0039-128x(94)90055-8, indexed in Pubmed: 7878688.

14. Yeh KY. Corticosterone concentrations in the serum and milk of lactating rats: parallel changes after induced stress. Endocrinology. 1984; 115(4): 1364-1370, doi: 10.1210/endo-115-4-1364, indexed in Pubmed: 6541120 . 
15. Hirasawa G, Takeyama J, Sasano H, et al. 11Beta-hydroxysteroid dehydrogenase type Il and mineralocorticoid receptor in human placenta. J Clin Endocrinol Metab. 2000; 85(3): 1306-1309, doi: 10.1210/jcem.85.3.6429, indexed in Pubmed: 10720080.

16. Yang K. Placental 11 beta-hydroxysteroid dehydrogenase: barrier to maternal glucocorticoids. Rev Reprod. 1997; 2(3): 129-132, doi: 10.1530/ror.0.0020129, indexed in Pubmed: 9414475.

17. Pereira AS, Giusti-Paiva A, Vilela FC. Central corticosterone disrupts behavioral and neuroendocrine responses during lactation. Neurosci Lett. 2015; 606: 88-93, doi: 10.1016/j.neulet.2015.08.018, indexed in Pubmed: 26297864.

18. Chang LL, Wun WSA, Wang PS. An inhibitor of 11- $\beta$ hydroxysteroid dehydrogenase type 1 (PF915275) alleviates nonylphenol-induced hyperadrenalism and adiposity in rat and human cells. BMC Pharmacol Toxicol. 2018; 19(1): 45, doi: 10.1186/s40360-018-0235-0, indexed in Pubmed: 30021644.
19. Lai CT, Gardner H, Geddes D. Comparison of Inductively Coupled Plasma Optical Emission Spectrometry with an Ion Selective Electrode to Determine Sodium and Potassium Levels in Human Milk. Nutrients. 2018; 10(9), doi: 10.3390/nu10091218, indexed in Pubmed: 30177589.

20. Yurdakök M, Oran O, Tekinalp G. Sodium and potassium levels in colostrum. Turk J Pediatr. 1991; 33(4): 231-234, indexed in Pubmed: 1814040.

21. Keenan BS, Buzek SW, Garza C, et al. Diurnal and longitudinal variations in human milk sodium and potassium: implication for nutrition and physiology. Am J Clin Nutr. 1982; 35(3): 527-534, doi: 10.1093/ajcn/35.3.527, indexed in Pubmed: 7199816.

22. Miciński J, Miciński J, Pogorzelska J, et al. Basic and mineral composition of colostrum from cows in different ages and calving period. Journal of Elementology. 2016(1/2017), doi: 10.5601/jelem.2016.21.2.1159.

23. Mastroeni SS, Okada IA, Rondó PHC, et al. Concentrations of $\mathrm{Fe}, \mathrm{K}, \mathrm{Na}, \mathrm{Ca}$, $\mathrm{P}, \mathrm{Zn}$ and $\mathrm{Mg}$ in maternal colostrum and mature milk. JTrop Pediatr. 2006 52(4):272-275, doi: 10.1093/tropej/fmk004, indexed in Pubmed: 16547068. 